\title{
The Constitutional VieW
}

\author{
Roberto Horácio de SÁ Pereira
}

\begin{abstract}
This brief paper is devoted to criticizing the widespread reading of Kant's first Critique, according to which reference to subject-independent objects is "constituted" by higherorder cognitive abilities (concepts). Let us call this the "constitutional view". In this paper, I argue that the constitutional reading confuses the un-Kantian problem of how we come to represent objects (which I call the intentionality thesis), with the quite different problem of how we cognize (erkennen) (which I call the "cognition thesis") that we do represent objects, that is, things that exist independently of the subject.
\end{abstract}

Keywords: Constitutional view; non-conceptual content; the puzzle theory; the cognition thesis.

\section{Introductory remarks}

The mainstream of Anglo-Saxon philosophy of the twentieth century assumes that perceptual reference is constituted by higher-order cognitive capacities: that is, without these capacities, either perception is reduced to mere sensations, which are devoid of reference, or perception refers only to mind-dependent entities. In the absence of a better name, I want to call this metaphysical claim the "constitutional view". In the first half of the twentieth century, the constitutional view grew from the work of Frege, Russell, and Carnap. In the second half of the twentieth century, it developed from the work of Strawson, Quine, and Davidson. ${ }^{1}$

However, as many still believe that the constitutional view has a Kantian affiliation, this paper is motivated by a criticism of the constitutional reading of Kantian theoretical philosophy. ${ }^{2}$ In Kantian scholarship, the constitutional view is invariably characterized as the view that, without concepts, we are left with a chaotic manifold of sensations that are devoid of reference: no subject-independent entity is represented. ${ }^{3}$ The constitutional reading is the natural consequence of two claims associated with Kant: (1) the traditional conceptualist reading, and (2) the misreading of the understanding as a rule-giver for syntheses.

The conceptualist reading of Kant is still hegemonic in Kantian scholarship. Kant's slogan "intuitions without concepts are blind" (A51/B75) is misread as if Kant was stating that sensible intuitions would be devoid of reference if they were without concepts. ${ }^{4}$ Thus, when Kant famously claims that: "objects can indeed appear to us without necessarily having to be related to functions of the understanding" (A89/B122, emphasis added), or that "appearances would nonetheless offer objects to our intuition, for intuition by no means requires the function of thinking," (A90-1/B122-3,

Principia 20(2): 165-177 (2016).

Published by NEL — Epistemology and Logic Research Group, Federal University of Santa Catarina (UFSC), Brazil. 
emphasis added) he is merely evoking a Cartesian-like "specter to be exorcized,"5 or a Hume-like sense-datum theorist ${ }^{6}$ to be ruled out by the Transcendental Deduction. The assumption here is that, without these categories, our experience would be reduced to a chaos or, to use James's famous words, to a great "blooming, buzzing confusion".

The second root of the constitutional view is the assumption that the understanding as a ruler-giver is responsible for creating reference for objects out of the chaotic manifold of sensations. That is what I call the puzzle theory. We are told that the understanding is not only the power that enables us to understand through concepts in judgments (what Kant calls "analytical unity"). As the rule-giver for the synthesis of imagination, the understanding also provides the instructions for the unification of the manifold of sensory states as if it were a mental activity of assembling the pieces of a puzzle in order to form a picture of reality. The understanding is the power of creating the intentional relation to objects out of the chaotic sensory manifold information that is given to our senses (what Kant supposedly calls "synthetic unity"). ${ }^{7}$

In this paper, I am not directly concerned with the defense of nonconceptualism. However, I am clearly on the side of the nonconceptualist readers. My primary concern here is with puzzle theory: that is, the idea that the representation of objects results from assembling pieces of a puzzle through a synthesis guided by the understanding. Appearances notwithstanding, I argue that the constitutional reading relies on a deep misunderstanding: it confuses the un-Kantian problem of how we come to represent objects (which I call the intentionality thesis), with the quite different problem of how we recognize (erkennen) that we do represent objects (which I call the cognition thesis): that is, subject-independent things. ${ }^{8}$ The problem with the constitutional reading is that Kant's word "cognition" (Erkenntnis) is actually a technical term meaning self-conscious representation, where our sensible intuition represents things that exist outside of us independent of the subject. My claim is entirely independent of any reading of Kant's transcendental idealism.

This brief paper is conceived in two contrasting sections. In the first section, I am going to retell the big story that has been told for centuries - puzzle theory - that is, how the representation of objects (the intentionality thesis) arises out the synthetic activity of the imagination, guided by the understanding as the rule-giver. The second section is devoted to undoing the misunderstanding in the constitutional reading: on the basis of the same passages, I argue that Kant never had in mind the intentionality thesis, but rather the cognition thesis. By means of sensible intuition, we already represent subject-independent objects in space and time. However, we can only recognize what we are blindly representing by means of empirical concepts, and we can only recognize through categories that what we are representing by senses exists subject-independently. 


\title{
The intentionality thesis
}

\section{The puzzle theory}

Let me begin by quoting the Kantian passage that leads to puzzle theory.

\begin{abstract}
Unity of synthesis in accordance with empirical concepts would be entirely contingent, and, were it not grounded on a transcendental ground of unity, it would be possible for a swarm of appearances (ein Gewühle von Erscheinungen) to fill up our soul without experience (Erfahrung) ever being able to arise from it. But in that case, all relation of cognition (Erkenntnis) to objects also disappears, since the appearances would lack the connection that universal and necessary laws demands, and would thus be intuition with no thought or cognition (Erkenntnis), and would therefore be as good as nothing for us. (A111. Emphasis in bold added)
\end{abstract}

This first section is devoted to the exploration of the intentionality thesis. Therefore, let us assume for the sake of argument that when Kant states swarm of appearances, he is referring to James's blooming, buzzing world of appearances: a chaotic manifold of sensory states devoid of representational content, as puzzle theory claims. Given this, Kant's problem is how someone in such a skeptic-like scenario could overcome the chaotic manifold of sensory states that are devoid of content and start to represent the subject-independent objects. That is what I refer to as puzzle theory, as I will explain now.

Puzzle theory begins with the assumption that animals and infants live in James's blooming, buzzing world of appearances. However chaotic and in flux those senseimpressions might be, they are all in time understood as forms of intuitions. Therefore, in puzzle theory, the first "objectivizing" step is described as follows:

Now in order for unity of intuition to come from this manifold information (as, say, in the representation of space), it is necessary first to run through and then take together this manifold information, which action I call the synthesis of apprehension, since it is aimed directly at the intuition, which to be sure provides this information but can never interpret it, and indeed is contained in one representation, without the occurrence of such a synthesis. (A99, emphases in cursive are added)

As subjective and inner sense-impressions, they all occur during time, as part of the succession of everything that is occurring. Therefore, the first thing the selfconscious mind undertakes is to run through these subjective inner sense-impressions and then integrate them (take them together) as pieces of the same unified picture of something. Three remarks are necessary here. First, the mind faces a manifold of sense-impressions as modifications of intuitions. Therefore, apprehension operates on subjective sense-impressions or ideas. Second, and most importantly, "running 
through" the manifold in time and "taking them together" are understood by puzzle theory as real processes that the mind performs, below the level of self-conscious thought. ${ }^{9}$ Third, as this operation is performed under the threshold of self-conscious thought, the result is not yet a representation of any object. The fundamental claim here is conceptualism: we can only represent subject-independent objects by means of concepts in thoughts. ${ }^{10}$

Let us review one of Kant's favorite examples. By means of the sight, a manifold of subjective and inner sense-impressions devoid of any reference are given as mere modifications of my mind. In that sense, they only exist inside me: sense-impressions (as of a roof), sense-impressions (as of a window), sense-impressions (as of a door) and so on. However, when I run through these successive inner sense-impressions and then take them together as pieces of a puzzle, then a conscious picture (as of a house) emerges. However, since I am not employing any concept, this representation does not picture a house that exists independently of me (the subject). According to the conceptualist reader, the representation of the existence of a subject-independent house, beyond assembling the pieces of the puzzle, requires the mastering of the concept of a house.

This first step in objectification is inseparable from the following step, which Kant defines as follows:

It is, to be sure, a merely empirical law in accordance with which representations that have often followed or accompanied one another are finally associated with each other. They are thereby placed in a connection in accordance with which, even without the presence of the object, one of these representations brings about a transition of the mind to the other in accordance with a constant rule. (A100)

However, the conscious representation of something (perception) could not be possible if there were not an empirical law that enables the mind to retrieve some past sense-impression, when this sense-impression is no longer present to my mind, by means of another sense-impression empirically associated with the first. For example, if I see the sense-impression of a boat navigating upstream at $t_{2}$, it prompts in my mind the retrieval of the sense impression of a boat navigating upstream at $t_{1}$, which was no longer present in my mind. Likewise, if I see the sense-impression of a door at $t_{2}$, it prompts my mind to retrieve the sense-impression of the window at $t_{1}$ or the sense-impression of a roof at $t_{0}$, which are no longer present. Therefore, puzzle theory requires the ability to retrieve the pieces of the puzzle when they are no longer present, through their association with pieces that are present in the mind.

Again, the empirical association operates directly on subjective sense-impressions or ideas. Second, even though it is passive, the empirical association is understood as a real process in the mind. ${ }^{11}$ Third, as this operation is performed under the level 
of self-conscious thought, the result is not yet a representation of any object. Again, the underlying assumption is conceptualism: only by means of concepts in thoughts can we refer to subject-independent objects.

To complete puzzle theory, a final operation of objectification is still required. That is what Kant calls the synthesis of recognition:

Without the consciousness that which we think is the very same as we thought a moment before, all reproduction in the series of representations would be vain. For it is a new representation in our current state, which would not belong to the act through which it had been gradually generated, and its manifold would never constitute a whole, since it would lack the unity that only consciousness can obtain for it. If, in counting, I forget the units that I now have before my senses, I would not cognize the generation of the multitude through this successive addition of one to the other, and consequently I would not cognize the number; for this concept consists solely in the consciousness of this unity of the synthesis.

The word "concept" itself could effectively describe this remark. For it is one consciousness that unifies manifold information that has been successively processed, and also reproduced, into one representation. (A103)

Therefore, apprehension and reproduction would be vain without concepts. According to puzzle theory, I could only recognize that the sense-impressions I have seen at different successive times all belong together by means of a concept, showing that they were all marks (Merkmale) of the same concept. For example, I am making a puzzle. I assemble pieces insofar as they fit together: the piece of a roof, the piece of a window, the piece of a door, and so on. However, even if I succeed in assembling all the manifold pieces of information, I will miss the whole picture if I do not possess the required concept of a house. Therefore, I can only recognize that the sense-impression as of a door that I am seeing at $t_{2}$, and the sense-impression as of a window that I saw at $t_{1}$, and the sense-impression that I saw at $t_{0}$, belong together as marks of the concept of a house, if I possess the concept of a house.

Now the puzzle theory faces the key question: what should we understand as the concept of the object of our representations:

And here it is necessary to explain what is meant the expression "an object of representations". We have said above that appearances themselves are nothing but sensible representations, which, like objects, must not be regarded in themselves, outside the power of representation. What does one mean, then, if one speaks of an object corresponding to and therefore also distinct from the cognition? It is easy to see that this object must be thought of only as something in general $=\mathrm{X}$, since outside of our cognition we have nothing that we could compare to this cognition as corresponding to it.

However, we find that our thought of the relation of all cognition to its object carries something of necessity. Since the latter is regarded as that which is

Principia 20(2): 165-177 (2016). 
opposed to our cognitions being determined at pleasure or arbitrarily, rather than being determined a priori, insofar as they are to relate to an object, our cognitions must also necessarily agree with each other in relation to it, i.e., have that unity that constitutes the concept of an object. (A104, emphasis added $)^{12}$

Therefore, according to puzzle theory, the subject-independent object of our representations is nothing over and above the unity of those same representations, according to a rule provided by a concept. In other words, the relation (Beziehung) to an object only emerges when we unify the inner subjective sense-impressions according to a rule of synthesis, which is provided by a concept. Kant provides us as examples the concepts of a triangle (A105) and the concept of a body (106) in the sequence. But let me stick to the a priori examples of the house. After assembling the sense impression piece by piece, I start to become related to an object when I unify those pieces according to the concept of a house. The house as the object of my representation is nothing but the unity of the pieces of the puzzle (the synthetic unity of representations) that I manage to assemble according to the instructions provided by the concept.

The best example of this reading can be found in the work of Henrich (1994). According to him, objects are complexes of predicates:

It is easy to see that our relations to objects cannot effect through such occurrences (the presentations of sensible qualities) alone. Regarding both what an object is and the attitude that makes possible its cognition, conditions are included in the thought of the object that cannot be satisfied by the presentations of sensible qualities as such. Whereas objects must satisfy certain requirements of constancy, a cognition that can be called "objective" can come about only through the successful application of criteria that allow a distinction to be drawn between objects that are merely putatively given and objects that are really given (1994, p.130; emphases in bold are added). (...) For this reason, we can never think of objects as simple entities beyond appearances. A multiplicity of presentations must always be ascribed to them. In this sense objects are themselves complexes or, in any event, are complexly characterized particulars. (1994, p.132, emphasis in bold are added).

\section{The cognition thesis}

To begin with, Kant's swarm of appearances is not James's blooming, buzzing world of appearances at all, that is, a chaotic manifold of sensory states devoid of representational content. Kant is clearly assuming that that a swarm of appearances can fill up our souls: that is, that objects can appear to our senses without experience 
(Erfahrung) and cognition (Erkenntnis). The error of the intentionality thesis is to mistake experience and cognition for mere representations of objects. Instead, they are technical terms. ${ }^{13}$ Cognition is neither the representation of objects nor the representation of subject-independent particulars. Instead, it is the realization that what we represent nonconceptually by the senses in fact exists subject-independently (cognition thesis). Therefore, what Kant is stating in the quoted passage of A111 is that, without empirical concepts, we could cognize what appears to as a swarm: that is, as something we could comprehend or understand. Empirical concepts are conditions for the cognition of objects (the cognition thesis) rather than conditions for representing objects (the intentionality thesis).

Second, the widespread assumption that without concepts our cognitive life would be James's blooming, buzzing world of appearances lacks any textual support. Worst then that, that assumption completely contradicts Kant's achievement in the Transcendental Aesthetic, according to which we represent objects in space and time without concepts and we can also represent space and time as a priori forms of all empirical intuitions as pure intuitions without the use of concepts.

The careful reader must remember that, in the Transcendental Aesthetic, Kant not only claims that space and time are the forms of sensible intuition. He also claims to have proven that space and time are pure intuitions: that is, they are not only the form of what appears to our outer and inner senses, but also immediate and singular representations of space (A25/B39) and of time (A32/B47) - immediate and singular representations of the spatiotemporal forms. In the particular case of space, Kant quite clearly claims that without any concepts whatsoever, including the concept of space, we are already able to represent an "infinite magnitude" (B40): the intentional object of our outer sense. Pure intuition of space is a paradigmatic case of nonconceptual content: without the category of quantity or any other spatial concept whatsoever, the subject is able to represent an infinite magnitude (as the intentional object of her outer sense), of course without recognizing or understanding what "an infinite magnitude" means. Kant goes beyond this and wonders how such pure intuitions are possible. It is at this moment that he introduces a further crucial concept: forms of human sensibility. We can only immediately represent a priori the forms of what appears to our outer sense and inner sense because those forms of appearances lie a priori in us as formal constitutions of our human sensibility (B41).

Longuenesse (1998) is the only conceptualist reader who is coherent in this respect. She clearly sees that, if Kant is assuming that without concepts our cognitive life would be reduced to James's blooming, buzzing world of appearances, we face the challenge of rewriting the Transcendental Aesthetic (1998, p.216). Considering that Kant rewrote his Deduction many times and his Refutation dozens of times, the fact that he never changed his Aesthetic is strong textual evidence that he never thought of intuitions without concepts as in James's blooming, buzzing world. 
Now let us return to apprehension and reproduction. To be sure, Kant's way of expressing himself suggests that he is postulating a necessary but still insufficient condition for representing objects from the manifold of the putative chaos of successive sense-impressions. On a closer look, he is not considering the intentionality thesis (how a representation of an object arises out of the manifold of sense-impressions), but rather the cognition thesis:

The synthesis of apprehension is therefore inseparably combined with the synthesis of reproduction. And since the former constitutes the transcendental ground of the possibility of all cognition in general (not only of empirical cognition, but also of pure a priori cognition), the reproductive synthesis of imagination belongs among the transcendental actions of mind, and we will also call this faculty the transcendental faculty of imagination. (A102, emphases added)

According to the intentionality thesis, apprehension is a necessary but insufficient condition for representing something as an object. Instead, apprehension is a necessary but insufficient condition for cognizing (erkennen) that which I am representing exists subject-independently. Let us rethink our example. By means of sensible intuitions, I see a house even when I lack the concept of HOUSE that is necessary for describing what I am representing (the nonconceptualist thesis). ${ }^{14}$ Therefore, I do not cognize that I am seeing a house or cognize that I am a subject-independent object. Now the first necessary but insufficient condition to cognize that I am seeing a subject-independent thing is to recognize that my mental states succeed one another in time. Second, I must run through those states and take them up together as cognitions of something independent and outside me in space. Therefore, I run through my successive sensory states in time (of a roof, of a door, of a window, etc.) and take them up together as cognitions of something independent and outside me in space.

But that is obviously not enough. For one thing, while I am contemplating the window of the house, I might forget seeing the roof or the door and so on. Therefore, I still possess no cognition that the object I am facing exists subject-independently, so reproduction is needed. While I am contemplating the window of the house, I must be able to retrieve the representations of the roof and of the door that are empirically associated with the representation of the window. The synthesis of reproduction is the further condition of cognition that ensures that what we see continues to exist subject-independently when we do not perceive it.

Finally, cognition of what we see requires concepts of objects. Again, I am able to represent some subject-independently existing things without possessing the relevant concept (nonconceptualist thesis). However, without some concept of an object (category of substance), I have no guarantee of cognizing that what I am now seeing is the same object that I have seen before. In Kantian terms, without the consciousness that what we think is the very same as what we thought a moment before, all 
reproduction in the series of representations would be vain for cognition that what my senses represent exists in fact subject-independently. The synthesis of recognition is the last condition of cognition that ensures that what we see is the same subjectindependent object we have seen before.

Now we must face the Kantian question: what is meant by the expression "an object of representations?" (A104). Kant does not state that our representation of an object carries something necessary so that our representations must necessarily agree with each other, or that the object must be seen as a necessary synthetic unity of representations (intentionality thesis). Instead, he states that our thought about the relation of all cognition to its object carries something of necessity, so that our cognitions must necessarily agree with each other in relation to the object and its concept (A104). Thus, the idea is not that the object itself is a synthetic unity of representations, let alone a complex entity composed of predicates, ${ }^{15}$ but rather that the cognition that the objects represented by our senses exist subject-independently requires agreement between the partial cognitions that are the concept of the object. Thus, if I cognize that a body represented by my senses exists subject-independently, then all partial cognitions that constitute the concept of a body (the cognition of the impenetrability of the body, the cognition of the extension of a body, the cognition of the heaviness of a body, etc.) must agree with each other as characteristic marks of the concept of body.

\section{Works of Kant}

References to Kant's works are given in the German Academy edition: Gesammelte Schriften, herausgegeben von der Königlich Preussischen Akademie der Wissenschaften, 29 vols. (Berlin: 1902-1983; 2nd ed., Berlin: De Gruyter, 1968, for vols. I-IX). They are indicated as follows: abbreviation of the title of the work, followed by Ak., volume, and page. For the Critique of Pure Reason, the references are shortened, in keeping with current practice, to the pagination of the original edition indicated by A for the 1781 edition, and B for the 1787 edition. All translations are mine.

\section{References}

Allais, L. 2009. Kant, non-conceptual content and the representation of space. Journal of the History of Philosophy 47(3): 383-413.

Allison, H. E. 1983[2004]. Kant's transcendental idealism. An interpretation and defense. New Haven: Yale University Press.

- 2015. Kant's Transcendental Deduction: An Analytical-Historical Commentary. Oxford: OUP.

Principia 20(2): 165-177 (2016). 
Baillargeon, R. 1987. Object Permanence in 3.5- and 4.5-Months-Old Infants. Development Psychology 23: 655-644.

Bennett. J. 1966. Kant's Analytic. Cambridge: Cambridge University Press.

Bowman, B. 2011. A Conceptualist Reply to Hanna's Kantian Non-Conceptualism. International Journal of Philosophical Studies 19(3): 417-446.

Burge, T. 2010. Origins of Objectivity. Oxford: OUP.

Cassirer, H. W. 1954. Kant's First Critique. London: George Allen \& Unwin Ltd.

Ginsborg, H. 2008. Was Kant a nonconceptualist? Philosophical Studies 137(1): 65-77.

George, R. 1981. Kant's sensationism. Synthese 47(2): 229-255.

Gomes, A. 2014. Kant on Perception: Naive Realism, Non-Conceptualism, and the B-Deduction. Philosophical Quarterly 64(254): 1-19.

Grüne, S. 2011. Is there a Gap in Kant's B Deduction? International Journal of Philosophical Studies 19(3): 465-490.

Hanna, R. 2005. Kant and nonconceptual content. European Journal of Philosophy 13(2): 247-290.

- 2006. Kant, Science, and Human Nature. Oxford University Press

- 2008. Kantian non-conceptualism. Philosophical Studies 137(1): 41-64.

- 2011. Kant's Non-Conceptualism, Rogue Objects, and The Gap in the B Deduction. International Journal of Philosophical Studies 19(3): 399-415.

Henrich, D. 1982[1994]. The Unity of Reason: Essays on Kant's Philosophy. Harvard University Press.

Kant, I. 1762[1992]. FSS.: Die falsche Spitzfindigkeit der vier syllogistischen Figuren AA. 2 (1762). The False subtlety of the four syllogistic figures. Trans. David Walford in collaboration with Ralf Meerbote. Ed. Paul Guyer and Allen W. Wood. Cambridge: Cambridge University Press, 1992.

- 1781[1998]. KrV.: Kritik der reinen Vernunft (1781). Critique of Pure Reason, ed. and trans. Paul Guyer and Allen W. Wood. Cambridge: Cambridge University Press, 1998.

- 1783[1985]. Prol.: Prolegomena zu einer jeden künftigen Metaphysik, die als Wissenschaft wird auftreten konnen, AK. 4 (1783). Prolegomena to Any Future Metaphysics That Will Be Able to Come Forward As Science, in Philosophy of Material Nature. Trans. J. W. Ellington. Indianapolis: Hackett, 1985.

—. 1800[1992]. JL.: Jäsche Logik, AA. 9 (1800). Logic, ed. J. B. [Jäsche Logic]. In: Lectures on Logic. Ed. and trans. J. Michael Young. Cambridge: Cambridge University Press, pp. 521-640, 1992.

- 1967. Letters: Philosophical Correspondence, 1759-1799. Ed. and trans. Arnulf Zweig. Chicago: University of Chicago Press.

- 1992. BL: The Blomberg Logic, AA. 24. In: Lectures on Logic. Ed. and trans. J. Michael Young. Cambridge: Cambridge University Press, pp. 15-246.

Longuenesse, B. 1998. Kant and the capacity to judge. Princeton University Press.

McLear, C. 2011. Kant on Animal Consciousness. Philosophers' Imprint 11(15).

Paton, H. J. 1937[1970]. Kant's Metaphysic of Experience. London: George Allen \& Unwin .

Stern, R. 1990. Hegel, Kant and the Structure of the Object. Routledge.

Strawson, P. F. 1966. The bounds of sense. London: Methuen.

Tolley, C. 2012. Kant on the Content of Cognition. European Journal of Philosophy 20(4): 200-228.

Principia 20(2): 165-177 (2016). 
Roberto HorÁcio de SÁ PEREIRA

Federal University from Rio de Janeiro

Rio de Janeiro, Largo de São Francisco 1

robertohsp@gmail.com

\section{Notes}

${ }^{1}$ The constitutional view is similar in several aspects to what Burge has called individual representationalism (Burge 2010, pp.138-154). In Burge's words: "The core assumption of the syndrome is that an individual cannot empirically and objectively represent an ordinary macro-physical subject matter unless the individual has resources that can represent some constitutive conditions for such representation." (2010, p.13). However, Burge is focused on the opposition between individualism and anti-individualism (also known as externalism). In contrast, my focus is on the opposition between higher-level (conceptualism) and lower-level cognitive capacities (nonconceptualism).

${ }^{2}$ Therefore, I must be clear from the outset that my concern here is of historical rather than of systematic nature.

${ }^{3}$ Cassier was one the first important Kantian scholars to suggest such a reading. He interprets Kantian sensible intuition as "mere occurrences of sense impressions in the mind" (1954, p.56), and then claims that, without concepts, "no proper awareness of anything is possible" (1954, p.118), and that "in the absence of original acts of understanding, there can be no consciousness of anything objective (...)" (1954, p.138).

However, the same reading can also be found in Allison:

(Without such self-conscious use of concepts) "nothing would be recognizable and our experience would be nothing but what William James famously referred to as "one great blooming, buzzing confusion" (Allison 2015, p.54).

Likewise, in Strawson:

(Without such self-conscious use of concepts): "we seem forced to conclude that there are particular subjective experiences of which the objects (accusatives) have no existence independently of the awareness of them." (1966, pp.100-1)

Bennett gives a further example of the same reading:

(Without such self-conscious use of concepts): "we live in a chaotic world of manifold data in which everything is in continual flux." (Bennett 1966, p.33)

${ }^{4}$ On a closer look, Kant is actually saying that without concepts we could not understand and hence cognize what our senses represent. Two prominent names in the recent nonconceptualist trend in the Kantian scholarship are Hanna (2005; 2006; 2011) and Allais (2009). Also worth mentioning are the recent works of McLear (2011) and Tolley (2013). The prominent names that arise in the conceptualist reaction are Ginsborg (2008), Grüne (2011), and Gomes (2014). However, we should remember that all of the major names in Kantian scholarship have been conceptualist readers of Kant: Allison (2015), Longuenesse (1998), Strawson (1966), and so on.

${ }^{5}$ See Allison 2015, p.54.

${ }^{6}$ See Strawson 1966, p.73.

Principia 20(2): 165-177 (2016). 
${ }^{7}$ The constitutional view is so widespread in Kantian scholarship that I can quote almost any famous Kantian scholar to illustrate it. Here, I limit myself to mentioning only a few representative names: Paton (1937/1970), Henrich (1982/1994), Longuenesse (1998), Allison (1983/2004) and (2015), George (1981), Stern (1990), et al.

${ }^{8}$ Regardless of Kant, the constitutional view is empirically false. There is a huge amount of data coming from experimental science, as cognitive psychology clearly indicates that there is perceptual reference to subject-independent entities that is quite independent of higherorder cognitive abilities. Baillargeon's drawbridge experiments (1987) are the best available evidence that infants are sensitive to the solidity of material objects. She conceives the following experiment. She habituated infants who were $4 \frac{1}{2}$-months old to a screen rotating vertically at $180^{\circ}$ on a table, rather like a drawbridge. She then placed a stationary object behind the screen so that it was completely occluded by the time the screen had been raised $60^{\circ}$. She was interested in whether the infants would distinguish between trials in which the screen stopped when it reached the place occupied by the object and trials in which the screen continued rotating (apparently passing through the object). In fact, the infants looked for longer during the second type of trial, which thus indicates that they found this novel and surprising. This is evidence of the infant's sensitivity to the impossibility of there being more than one object in a single place at one time.

${ }^{9}$ In Strawson's words: "At times Kant seems to turn for an answer to a special kind of "transcendental self-consciousness" associated with the activity of the faculty of understanding. The key unity of consciousness, it seems, is to be sought in the fact that the connectedness of our perception is produced by the activity of the mind." (1966, p.94)

${ }^{10}$ Paton, one of the most influential Kantian Scholars, put this as follows:

"The full description of the synthesis of apprehension is the synthesis of the apprehension of ideas, as modifications of the mind in intuition. This shows that apprehension qua apprehension is concerned with ideas as these are present to us in inner sense. These ideas may be called subjective in the sense that for mere apprehension (that is apprehension in abstraction from thoughts) they are not ideas of an object." (1937/1970: part I: 360).

${ }^{11}$ Paton comments on this as follows:

"Apprehension involves more than taken up the given at the moment when it is given. Since our awareness of a color, and still more our awareness of a concrete object, is a process which occupies time, we must, if we are to have experience of objects, be able to keep before our minds what has been given, when it is no longer being given. This is the work of memory, without which there could be no knowledge."(1970, I, p.363)

12 This passage echoes Kant's Second Analogy:

"We have representations in us, of which we can also become conscious. But let this consciousness reach as far and as exact and precise as one wants, there always remain only representations, i.e., inner determinations of our mind in this or that temporal relation. Now how do we come to posit an object for these representations, or ascribe to their subjective reality, as modifications, some sort of objective reality? Objective significance cannot consist in the relation to another representation (of that which one would call the object), for that would simply raise a new the question: How does this representation in turn go beyond itself and acquire objective significance in addition to the subjective significance that is proper to it as a determination of the state of mind? If we investigate what new characteristic is given to our representations by the relation to an object, and what is the dignity that they thereby

Principia 20(2): 165-177 (2016). 
receive, we find that it does nothing beyond making combination of representations necessary in a certain way, and subjecting them to a rule; and conversely objective significance is conferred on our representations only insofar as a certain order in their temporal relation is necessary". (A197/B242-3)

13 "Cognition" (Erkenntnis) is a technical term in Kant's theoretical philosophy. Kant contrasts erkennen to kennen. To put it in Russell's famous terms, Erkennen is understood by Kant as a form of propositional knowledge or understanding: "I erkennen dass (...)". In contrast, kennen is understood as an immediate form of knowledge by acquaintance: an objectual knowledge (see FSS., §6, AA, 2, p.60; BL., fifth section, §139, AA. 24, pp.132-133; pp.103104; JL., VIII, AA., 9, p.65; p.569).

${ }^{14}$ This famous passage better supports this reading:

"If a savage sees a house from a distance, for example, with whose use he is not acquainted, he admittedly has before him in his representation the very same object as someone else who is acquainted with it determinately as a dwelling established for humans. But as to form, this cognition of one and the same object is different in the two. With one it is mere intuition, with the other it is intuition and concept at the same time." (LOG, introd., V, AA, 9, 33; pp.544-545)

Kant's point is that sensible intuition and concepts are two different and quite independent forms, or ways, of cognizing the same dwelling place. Prior to and independently of the conceptual recognition (erkennen) of the seen object as a dwelling that is established for humans, the savage is already able to refer to the same subject-independent object and to represent it as a bodily particular that appears from a certain distance, with a given shape, etc. Therefore, the savage's sensible intuition is blind, but not in the sense that it either lacks reference or that it refers only to "mere representation." Rather, it is blind to the fact that what the savage sees is a dwelling established for humans. In other words, without the concept of a dwelling established for humans, the savage simply cannot understand and hence know the subject-independent object that his intuition represents.

Simple-minded animals and nonlinguistic infants probably lack the Kantian categories of substance, causality, etc. They certainly cannot know or understand what their perceptual experience is representing. However, this dictum takes no position on whether perceptual experience without concepts lacks the power of reference.

${ }^{15}$ In this sense, the most bizarre reading of Kant's concept of object is Henrich's (1994), quoted above.

Principia 20(2): 165-177 (2016). 